\title{
A busca de um novo regime de mobilização da força de trabalho em uma empresa de laticínios uruguaia
}

Pedro Robertt*

\section{Introdução ${ }^{1}$}

A reestruturação produtiva levada adiante pelas empresas capitalistas, nas últimas décadas do século XX e início do século XXI, é formada por mudanças técnicas e organizacionais, e também por novos discursos e políticas gerenciais. Neste artigo focaliza-se esses discursos e políticas, ${ }^{2}$ pois eles representam uma parte central da busca de uma nova forma de organização

* Doutor em Sociologia pela Ufrgs. Especialista nas áreas de sociologia do trabalho e sociologia dos movimentos sociais. Membro do grupo de pesquisa "Processos Participativos na Gestão Pública" da Ufpel. Email: probertt21@gmail.com

1 As duas primeiras partes deste artigo são seções modificadas de capítulos da tese de doutorado do autor: "Reestruturação produtiva e social em uma empresa globalizada. O caso da Conaprole no Uruguai”, defendida, em 28 de abril de 2006, no Programa de Pós-graduação em Sociologia do Instituto de Filosofia e Ciências Humanas da Universidade Federal de Rio Grande do Sul (Robertt, 2006).

2 Para conferir as mudanças técnicas e organizacionais referidas pode-se consultar a tese citada do autor, principalmente o capítulo 3 (Robertt, 2006).

\begin{tabular}{|c|c|c|c|c|c|}
\hline Civitas & Porto Alegre & v. 7 & n. 1 & jan.-jun. 2007 & p. 109-129 \\
\hline
\end{tabular}


do trabalho. Ainda mais, eles constituem, como será argumentado, um elemento relevante de um novo regime de mobilização da força de trabalho.

Cumpre esclarecer que o processo de reestruturação produtiva, em todas suas dimensões, não se impõe necessariamente de forma unilateral de acordo com os objetivos empresariais. Na tese do autor (Robertt, 2006), mostra-se a constituição da empresa como um campo de lutas, verificando-se a oposição dos trabalhadores sindicalizados ao fechamento e deslocamento de linhas e plantas de produção, aos novos processos de trabalho e aos discursos e políticas gerenciais. Neste artigo, privilegia-se a análise do projeto empresarial, mas isso não significa a inexistência de fortes tomadas de posição daqueles que sustentam pontos de vistas discordantes, as quais, ainda que de forma subordinada, acabam afetando a direção geral do processo de reorganização da empresa. Em alguns momentos deste artigo pode ser notada a interferência sindical no processo geral de reestruturação, embora se privilegie aqui o projeto empresarial.

A exposição deste artigo divide-se em três partes: uma primeira, dedicada a avaliar a emergência e difusão, nos anos 1990, de novos discursos e políticas gerenciais; uma segunda, que expõe o estudo de caso realizado na Conaprole, empresa de laticínios uruguaia, na qual tem se registrado, nas últimas décadas, um forte processo de reestruturação que inclui uma nova orientação gerencial no sentido indicado acima; e, finalmente, uma terceira, que apresenta as considerações finais sobre o caso estudado.

Nas considerações finais mostra-se que a proposta de um novo regime de mobilização de força de trabalho, presente na Conaprole, está de acordo com as tendências das transformações empresariais no capitalismo contemporâneo. Conceitos como flexibilidade, competência, polivalência, confiança, envolvimento e adaptabilidade fazem parte do management da empresa, bem como a individualização na gestão dos assalariados. Contudo, revela-se que o avanço desse regime de mobilização da força de trabalho só se desenvolveu parcialmente, ao ser detectada uma maior flexibilidade junto com um escasso envolvimento dos trabalhadores com o novo projeto gerencial. 


\section{Os novos discursos e políticas gerenciais dos anos 1990: a difusão do modelo japonês e de um novo regime de mobilização da força de trabalho}

Para determinar quais são as principais características observadas nos novos discursos e políticas gerenciais dos anos 1990 é necessário, antes de mais nada, trazer os elementos característicos do modelo japonês, no que refere ao tipo de trabalhador procurado, devido à forte influência deste modelo na visão gerencial mais recente. No modelo japonês, de forma semelhante ao taylorismo e ao fordismo, procura-se um determinado tipo de trabalhador. Por exemplo, para Taylor o trabalho mental teria que estar concentrado nas gerências. Em concordância com isso, o propósito do taylorismo era substituir tanto quanto possível a autonomia do trabalhador pelo trabalho prescrito.

O perfil de trabalhador requerido pelo modelo japonês está associado aos conceitos de polivalência, flexibilidade e adaptabilidade às mudanças que se processam no mercado. Outros conceitos associados ao modelo japonês são os de qualificação, em termos de capacidade de tomar decisões, de desenvolvimento cognitivo e de desenvolvimento comportamental no trabalho.

Quanto ao aspecto cognitivo, conforme analisado por diversos autores, à diferença da gerência científica taylorista, o modelo japonês envolve os operários em atividades de engenharia e de planejamento. No que diz respeito ao âmbito comportamental, procura-se que sejam interiorizados, através da participação dos trabalhadores em pequenos grupos, os valores da empresa. Essa participação se dá num contexto produtivo que promove a competição e o orgulho de pertencer à empresa. A competição é incentivada tanto entre os trabalhadores dentro do grupo quanto entre os que pertencem a grupos diferentes. Segundo Malaguti (1996), a cooperação, a responsabilidade e a autonomia fazem parte do perfil do trabalhador buscado pelas empresas japonesas. Com isso diminuem fortemente as necessidades de supervisão da tarefa realizada pelas chefias, centrais nos modelos fordistas e pré-fordistas. O trabalhador japonês não precisa do controle das chefias, pois ele controla a si próprio e a seus colegas (Malaguti, 1996, p. 51-52).

Assim, o modelo japonês procura utilizar toda a capacidade produtiva do trabalhador. Conforme Paulani (2001, p. 708), técnicas de gestão como a coresponsabilidade do trabalhador e os mecanismos participativos são incorpo- 
rados à lógica da acumulação. Com Ohno (criador do modelo toyotista), sempre segundo a autora, trata-se de fazer um usufruto total (quantitativo e qualitativo) da força de trabalho.

Os discursos e práticas gerenciais difundidos desde os anos 1990, assim como os atuais processos de reorganização das empresas, são herdeiros dos aspectos mencionados do modelo japonês. Além disso, os discursos gerenciais representam uma força material tão importante quanto as novas formas de organizar o trabalho, pois apresentam uma crítica aos métodos de racionalização do trabalho anteriores - por exemplo, à divisão taylorista entre concepção e execução - incorporando aspectos culturais de identidade dos trabalhadores com a empresa (De La Garza Toledo, 2000, p. 158). Trata-se de valores, idéias e ideologias que pregam o envolvimento dos trabalhadores no processo de produção e o seu alinhamento com os objetivos traçados pelos proprietários da empresa (Supervielle; Stolovich, 2000, p. 364-365).

Alguns autores, como De La Garza Toledo (2000), Novick (2000), Bourdieu (1996), Pialoux (1996), e Beaud e Pialoux (1999), têm adotado o conceito de management participativo, que envolve um conjunto de técnicas de persuasão desenhadas para que os trabalhadores se incorporem de forma cognitiva e comportamental ao processo de produção. Da literatura consultada, pode-se extrair uma série de dimensões no discurso e prática gerenciais, que fazem parte da proposta de management participativo, tais como: (a) implantação dos círculos de qualidade; (b) co-responsabilidade do trabalhador (que passa a ser considerado como colaborador ou operador); (c) longo treinamento e novos sistemas de qualificação; (d) reformas profundas do sistema de atitudes (por exemplo, uso de formas lingüísticas mais pessoais entre chefes e subordinados: uso do pronome "tu" em vez de "o senhor"); (e) introdução de monitores (em oposição às antigas hierarquias); (f) transformação dos antigos departamentos de pessoal em departamentos de Recursos Humanos; (g) reorganização da oficina; e (h) estímulo à inovação e à comunicação.

Ao se avaliar, em conjunto, os novos discursos e práticas gerenciais, visualiza-se que o que está em jogo é um novo regime de mobilização da força 
de trabalho, ${ }^{3}$ caracterizado por direções empresariais que valorizam o envolvimento individual dos empregados, sem referência a coletivos como o sindicato. $\mathrm{O}$ conceito de competência ocupa um lugar central no novo regime de mobilização da força de trabalho. A qualificação como critério para ocupar um posto baseado nos saberes (formação curricular) e no savoir-faire (destrezas práticas) é substituída pela competência que acrescenta aos anteriores o savoir-être. Este último, como parte central do novo regime de mobilização da força de trabalho, tem o significado de integrar as atitudes dos trabalhadores diante da gerência e obter sua disponibilidade temporal, intelectual e comportamental diante das exigências do trabalho (Durand, 2003a, p. 151).

O novo regime de mobilização da força de trabalho inclui alterações das dimensões cognitivas e comportamentais expressas, sobretudo, nos conceitos de flexibilidade, confiança, colaboração, envolvimento, saber-fazer, saberser, receptividade e adaptabilidade. Esse novo regime pode, aliás, implicar em uma modificação do habitus operário, principalmente, no que se refere ao processo produtivo e à identidade do trabalhador com os valores da empresa. ${ }^{4}$

Conforme Daniele Linhart (1994), o management participativo consiste em uma ferramenta que busca integrar o espaço da empresa pondo em conta-

3 Segundo Durand (2003b, p. 191-193), o regime de mobilização do trabalho é um dos três pilares da "combinatória produtiva pós-fordista", sendo os outros dois a generalização do fluxo tensionado e o trabalho em grupo. Trata-se de motivar os trabalhadores, especialmente os de execução, a cooperar. A motivação baseia-se na construção de valores sociais comportamentais que correspondam às expectativas dos empregadores. Para isso, algumas das características principais requeridas da força de trabalho são: aceitação do fluxo tensionado; concordância com as exigências técnicas de qualificação e de disponibilidade horária; de autonomia e tomada de decisões e de aptidões para o trabalho em grupo. Por sua vez, conforme Durand (2003a, p. 139), o fluxo tensionado é o mecanismo que, nos métodos de produção mais modernos, "[...] organiza a disciplina (e o modo) do trabalho por meio do fluxo contínuo de todas as atividades (incluindo o trabalho intelectual)".

4 O habitus conceito desenvolvido na extensa obra do sociólogo Pierre Bourdieu. Pode-se consultar, por exemplo, Bourdieu (1983, p. 60-61). O habitus operário, entende-se neste artigo, pode incluir a realização de determinadas tarefas no trabalho, a aplicação de conhecimentos específicos, a obediência às normas do processo produtivo, a adoção de sugestões propostas pelas chefias, a identidade com os valores da empresa, o relacionamento quotidiano com os colegas, a participação nas assembléias do sindicato e a adesão a um partido político, a vida familiar em um bairro popular e as reuniões e festas com colegas ou com amizades fora da fábrica. A hipótese que aqui apenas se assinala é que um novo regime de mobilização da força de trabalho significaria uma modificação do habitus operário, no mínimo, no espaço restrito da empresa. 
to os diferentes setores que fazem parte dela. Trata-se de uma ferramenta utilizada para uniformizar e homogeneizar o espaço interno da empresa. Assim, pessoas de diferentes serviços e posições dentro da empresa são reunidos em grupos com o objetivo de potencializar a compreensão mútua. A autora também destaca que um dos elementos fundamentais da transformação do trabalho é a "individualização do tratamento e da gestão dos assalariados" (Linhart, 2000, p. 17). Na análise do caso francês, a autora afirma que a individualização complementa-se com o isolamento geográfico dos postos de trabalho devido às novas tecnologias informatizadas.

Essa individualização, segundo Linhart (1994, 2002), teve início nos anos 1970, com as seguintes políticas: a difusão dos horários variáveis e das gratificações individuais; a revisão das classificações para introduzir elementos mais pessoais de avaliação e as tentativas participativas através dos círculos de qualidade. No caso francês, a individualização é expressa na forma em que se aumentam os salários; no ajuste das formações e dos percursos personalizados dentro da empresa à nova situação, em uma mobilidade cada vez maior de todos; nas reclassificações que quebram as grandes categorias coletivas; e na instauração da entrevista de avaliação individualizada - duas entrevistas anuais do assalariado com seu superior hierárquico - durante a qual ele deve definir seus objetivos e, em seguida, avaliar seu próprio desempenho (Linhart, 2000, p. 17). As políticas de individualização dos salários, particularmente, começaram com os quadros superiores, estendendo-se cada vez mais a categorias de operários e empregados (Linhart, 1994, p. 42). As políticas enunciadas operam no sentido de minimizar o lugar do coletivo e privilegiar a dimensão individual (Linhart, 1994, p. 85).

Linhart (2000) acrescenta que um dos aspectos importantes da modernização, no caso francês, é o trabalho que as empresas fazem sobre a subjetividade do trabalhador. A autora menciona, como elementos que compõem esse empreendimento, os dispositivos participativos (círculos de qualidade e grupos de expressão direta e coletiva) e as campanhas de mobilização em torno da definição do projeto de empresa segundo a certificação da qualidade, a comunicação e a informação (Linhart, 2000, p. 19). De acordo com a autora, procura-se aproveitar todos esses momentos para transmitir os valores da empresa e obter a adesão dos trabalhadores. 
Para Boltanski e Chiapello (1999 apud Nardi, 2002), nos anos 1990 surgiu um novo discurso gerencial, um novo espírito do capitalismo, diferenciado do existente nos anos 1960, associado à empresa enxuta, ao trabalho em rede e à noção de colaboradores. Conforme esses autores, esse discurso é fortemente influenciado pelas técnicas japonesas de gestão referidas acima. Alguns de seus princípios orientadores são: a existência de empresas que aprendem, de líderes e coordenadores de equipe que substituem antigos diretores e gerentes, da confiança em troca da hierarquia, da gestão de pessoas em vez do manejo de "recursos humanos", da discussão de competências (técnica e emocional) em vez de qualificações e do emprego de "colaboradores" em vez de trabalhadores. Outro elemento detectado por esses autores é o deslocamento do controle do exterior (do cronômetro, da produtividade, das chefias) para o interior (o autocontrole), mediante a assimilação da cultura e dos objetivos da empresa.

Ao contrário do modelo dos anos 1960 e 1970, assentado na segurança de uma racionalidade burocrática, no atual, conforme os autores citados, são promovidos o risco, a mobilidade e a mudança. Para o discurso que se implanta, as causas da mudança são exteriores à empresa: o grande responsável é o processo de globalização e, principalmente, as conjunturas do mercado internacional. Difunde-se a idéia de que o sucesso da empresa e a sorte do trabalhador dependem da satisfação do "cliente externo" (o mercado). Se o controle é deslocado para fora da empresa, dentro dela os trabalhadores sentem a pressão do denominado "cliente interno". Os trabalhadores passam a ser "clientes internos" uns dos outros, dentro de uma rede onde não pode haver erros (Boltanski e Chiapello, 1999 apud Nardi, 2002, p. 170-190).

Alguns autores identificam contradições no discurso gerencial. Uma delas consiste em convocar os trabalhadores simultaneamente para a participação grupal e para a sua contribuição individual, associada à idéia de concorrência interna com os colegas (Pialoux, 1996). Contudo, Linhart (1994) questiona esta aparente contradição entre, de um lado, a promoção de comportamentos cada vez mais individualistas e, de outro, a busca de novas formas de sociabilidade dentro da empresa. Para essa autora, trata-se de um projeto coerente que busca criar indivíduos que interiorizem as dificuldades da empresa; sejam leais e competentes; e participem em "coletivos modernos", baseados numa solidariedade diferente dos "coletivos tradicionais" como os sindicatos, que ainda carregam uma herança de conflitos. 
As contribuições dos diferentes autores, analisadas aqui, chamam a atenção para os discursos e práticas gerenciais associados às novas formas de organização do trabalho. Esses discursos e práticas são relevantes, não por representarem uma justificação ideológica dos novos métodos de produção (pois não se trata de uma superestrutura encobridora dos processos reais), mas por fazerem parte da organização do trabalho que se pretende instaurar, pois esta necessita de trabalhadores que aceitem fazê-la funcionar no dia-adia. As formas de organização do trabalho, alternativas ao taylorismo, são acompanhadas de discursos e práticas gerenciais que procuram criar um novo regime de mobilização da força de trabalho. Este necessita de trabalhadores que estejam dispostos a se envolver com os objetivos da empresa, a serem flexíveis, adaptáveis e multifuncionais e a cederem seus conhecimentos. Nesse novo regime, a força de trabalho, por sua vez, deverá ser mais flexível, confiante, colaboradora, envolvida, disposta a contribuir com seu conhecimento, receptiva e adaptável.

\section{Os novos discursos e políticas gerenciais em uma empresa de laticínios uruguaia}

A Conaprole (Cooperativa Nacional de Produtores de Leite), fundada em 1936, é uma empresa dedicada à elaboração de leite e derivados lácteos, com características, na sua origem, de empresa privada de interesse público. ${ }^{5} \mathrm{Com}$ forte posicionamento no mercado interno e crescente presença no mercado global, desde final dos anos 1990 a Conaprole vem passando por um forte processo de reestruturação produtiva caracterizado, principalmente, pelo fechamento, transferência e criação de novas unidades industriais e pelo enxugamento no número de trabalhadores. No processo de reestruturação muitos trabalhadores são deslocados junto com as linhas e plantas de produção. Também vem sendo implementados processos de renovação tecnológica, informacional e organizacional e difundidos novos discursos e políticas gerenciais. ${ }^{6}$ Neles busca-se um trabalhador que desenvolva elementos associa-

Com forte responsabilidade na expansão do mercado de consumo interno por determinação do Estado nacional, a Conaprole teve durante várias décadas o monopólio de fornecimento de leite na capital do país.

6 A pesquisa foi efetuada nos anos de 2003 e 2004. 
dos a uma nova organização do trabalho, que vem sendo denominada, neste artigo, de novo regime de mobilização da força de trabalho.

De acordo com depoimentos registrados em entrevistas com chefes e gerentes da Conaprole, constata-se a importância dada ao desenvolvimento da dimensão cognitiva dos trabalhadores (o aprender a aprender e a valorização da elaboração conceitual sobre o esforço físico), a adaptação às mudanças e o desempenho de múltiplas tarefas. Esses elementos apontam para a construção de um novo regime de mobilização da força de trabalho, que pode chegar a significar também, caso o mesmo venha a ter sucesso na sua implementação, uma modificação no habitus operário no que se refere ao envolvimento do trabalhador na organização do trabalho.

Assim, os novos discursos gerenciais difundidos no âmbito do mercado global circulam também pela Conaprole. Conceitos como os de cliente interno, trabalhador satisfeito, competência e polivalência procuram ser incorporados e difundidos ao largo da organização por diferentes gerências e chefias. $^{7}$

Entre os quadros gerenciais e de chefias predomina o discurso da necessária transformação da empresa e da força de trabalho. As determinantes de um mercado global inconstante justificam, nesse discurso, a necessidade de mudança. Os seguintes depoimentos, de chefes da Conaprole de diferentes plantas, ilustram a interiorização do discurso da mudança. Um dos chefes entrevistados afirmou:

Siempre digo "el proceso de cambio" por más que yo lo estudié en teoría, el proceso de transformación que sufre una empresa, es un organismo vivo como cualquier sociedad. Incluso yo muchas veces me pregunto, que yo estoy en un proceso de formación [...] Sé por un lado que esta empresa tiene que cambiar porque sino no crece [...] pero por otro lado está lo interno, cómo procesás todos esos cambios internamente es todo un tema (entrevista com representante da empresa).

\footnotetext{
Na nomenclatura da empresa, os gerentes são aqueles que comandam grandes áreas da organização (industrial, gestão financeira, recursos humanos, comercial e outras) bem como o cargo de direção geral (gerente geral). Por seu turno, os chefes incluem responsáveis das plantas industriais e supervisores nos setores de produção e de administração.
} 
Do mesmo modo, outro chefe da Conaprole declarou:

Cuál es el motivo del cambio y de acuerdo a eso cómo cambiar, no proscribir que no cambie, aferrarse. Es el ejemplo del capitán que se aferra al mástil. Todo cambia, la alternativa que te dicen que tenés que ser flexible, entonces hay que ver cómo insertarse, la fortalezas y las debilidades. Vivimos en la sociedad de cambio y hay que trabajar las debilidades. La sociedad del conocimiento, del PC, precisamos de capacitación interna, del involucramiento del trabajador para que la empresa funcione y el cliente que es el productor sea satisfecho (entrevista com representante da empresa).

Na empresa estudada, o discurso e as políticas orientadas aos trabalhadores podem ser divididos em três grandes blocos: um primeiro sobre a flexibilidade; um segundo sobre as competências cognitivas e comportamentais; e um terceiro sobre a individualização. Esses são pilares para a construção de um novo trabalhador associado a alterações na organização do trabalho.

Como foi destacado por Hirata (2002, p. 342), a flexibilidade tem sido uma das dimensões principais buscadas pelas empresas, através do recurso às inovações tecnológicas e organizacionais. No caso da Conaprole, a flexibilidade da força de trabalho tem sido favorecida, nos últimos anos, pelo próprio processo de reestruturação espacial. A transferência e fechamento de linhas e de unidades industriais inteiras, com deslocamento dos trabalhadores, fez com que a força de trabalho aceitasse ser mais flexível quanto ao posto de trabalho e até mesmo quanto ao local de trabalho, como forma de conservar o emprego. Esse processo é assim visualizado por um representante da empresa:

[...] antes teníamos la rigidez en plantas donde una persona de un sector no se movía. Estaba en al estructura del trabajador y de la dirección también [...] hoy con este tema de que los trabajadores están acostumbrados a ir de una planta a otra, flexibilidad de planta está unido a mantener un puesto de trabajo. Porque el que no aceptaba eso, decíamos "no hay alternativa, sino va al seguro de paro" [seguro de desemprego]. [...] Se dijo a la gente que quería, y eso va levantando mitos, o sea en esta planta secaba polvo, en esta planta hacía queso y después iba a trabajar de mecánico a otra, en su cabeza los padrones cambian (entrevista com representante da empresa).

A empresa busca implantar um sistema de trabalho com trabalhadores mais flexíveis e, em boa medida, o tem conseguido como resultado do processo de reestruturação espacial. Observe-se que a última traz como conse- 
qüência a flexibilidade funcional. O operário trabalha onde a Conaprole lhe proporciona uma tarefa, ${ }^{8}$ portanto, não tem outra alternativa senão a de se adaptar ao posto de trabalho que lhe é proposto, seja onde for.

Existe um projeto gerencial de formação de um trabalhador mais capacitado, motivado e envolvido com a tarefa, bem como mais flexível, associado a novas formas de organização de trabalho. Uma medida de flexibilidade no uso da força de trabalho assinalada como projeto nos depoimentos gerenciais diz respeito ao fato dos trabalhadores poderem tirar, em vários períodos, as férias que lhes correspondem anualmente. A legislação uruguaia estabelece que as férias anuais do trabalhador (20 dias no mínimo, sem contar sábados e domingos) devem ser tiradas em um ou dois períodos, de no mínimo 10 dias cada. A proposta de dividir as férias anuais em mais vezes implica em uma maior flexibilidade no tempo de uso da força de trabalho. Outra proposta de flexibilidade se refere ao horário de trabalho. Em determinadas unidades industriais, propõe-se que os trabalhadores desempenhem horários superiores à jornada de oito horas. Quando não houver produção na planta (por exemplo em alguma unidade industrial em que se produz leite em pó) eles poderiam receber seu salário por oito horas de trabalho trocando as horas suplementares acumuladas (o chamado banco de horas utilizado por algumas empresas no Brasil). Outra alternativa proposta é a de que em algumas plantas se faça uma estimativa por semana prevendo, por exemplo, que em uma semana de 48 horas de trabalho, o trabalhador faça 12 horas em quatro dias e fique liberado o resto da semana. ${ }^{9}$

Neste ponto colocam-se as questões relacionadas com o desenvolvimento de competências cognitivas e comportamentais e com a multifuncionalidade. Com base em Gorgeu, Mathieu e Pialoux (2003), a competência é definida como o uso de diversos conhecimentos para levar adiante determinadas tarefas enquanto que a multifuncionalidade está vinculada à capacidade para transitar entre vários postos. Assim, a competência tem a ver com o fato de o trabalhador possuir vários conhecimentos ou desempenhar atividades em

8 Existem acordos, entre a direção da empresa e a organização sindical, pelos quais se estabelece que frente à escassez de trabalho em um setor ou planta de produção, o trabalhador pode ser deslocado de seu posto de trabalho.

9 Até a época da pesquisa tanto a organização sindical quanto a legislação trabalhista colocavam obstáculos à efetivação da flexibilidade de horário. 
ofícios periféricos à produção, como a manutenção, a qualidade e a logística. Ela envolve o trabalho intelectual, o domínio de diversos conhecimentos e a capacitação para decidir com base nesses conhecimentos. Já a multifuncionalidade refere-se ao aumento do número de tarefas realizadas por cada trabalhador. Conforme os autores citados a multifuncionalidade implica na capacidade de uma pessoa conhecer e ocupar vários postos de trabalho. $\mathrm{Na}$ Conaprole, observa-se nos depoimentos de gerentes e chefes a difusão de conceitos como os de competência e de multifuncionalidade (também de polifuncionalidade ou de polivalência), embora não se faça a distinção conceitual que se tem feito aqui.

[...] se está dando de hecho eso. Antes era mucho más rígido, este era mi puesto y yo no me movía de acá. Eso de hecho se fue dando, la polivalência. No es aceptada [pela organização sindical]. Estas cosas tienen problemas de tabúes ideológicos, porque no acepto tal palabra, tal cosa. De repente no acepto flexibilización y acepto adaptabilidad, porque lo estoy haciendo. Estamos adaptando. Es parte de irnos dando otras competencias. Nuestra empleabilidad, la capacidad de adaptación a todos los cambios y poder ser empleable por esta empresa o por otra y mejorar mi calidad de vida. Ese es un poco ese término (entrevista com representante da empresa).

Pode-se perceber, no depoimento anterior, que conceitos como os de polivalência ou multifuncionalidade fazem parte de um campo semântico que vai sendo difundido junto com termos como flexibilidade, competência, adaptabilidade, empregabilidade, trabalhador autônomo, grupos ou trabalho em equipe, comunicação e liderança. Trata-se de um projeto de trabalhador que já não permaneça especializado em uma única tarefa, ou fixo em um posto de trabalho.

A direção da empresa também tem apontado a necessidade de mudança na definição dos postos de trabalho. As categorias associadas aos postos de trabalho existentes na Conaprole datam de 1971. Muitas definições de categorias já não condizem com as tarefas realizadas e esse é um dos motivos para a procura de uma nova classificação. Por exemplo, a introdução da informática modificou substancialmente as características das tarefas. O mesmo pode ser dito em relação ao processo de trabalho, cada vez automatizado, com a conseqüente desaparição de tarefas manuais. Na classificação das tarefas, por exemplo, existia, conforme depoimento de representante da empresa, na recepção de leite, a categoria de "virador de tarros" que correspon- 
dia ao trabalhador que recebia o produto em tarros e o colocava - fazendo uso de força física - em grandes recipientes. $\mathrm{Na}$ época da pesquisa essa tarefa já era feita através da conexão das mangueiras do caminhão-cisterna com as da planta, e comandada de forma automatizada desde uma cabine. Outro forte motivo para a redefinição das categorias é, conforme depoimentos de representantes da empresa, a procura de acepções mais próximas a uma força de trabalho multifuncional ou com diferentes competências. Em relação a esta última dimensão, existe um projeto gerencial de trabalhadores com conhecimentos em eletro-mecânica e de operários de produção para que adquiram conhecimentos em elétrica ou em mecânica.

As competências cognitivas e comportamentais, segundo bloco temático enumerado nos discursos e políticas gerenciais, estão fortemente vinculadas à proposta de flexibilidade, pois não se trata de qualquer conhecimento ou atitude. Trata-se de competências vinculadas ao domínio de diversos conhecimentos e a uma atitude de envolvimento ("vestir a camisa da empresa") e de disponibilidade para assumir múltiplas tarefas, associada à idéia de multifuncionalidade. Por isso a perda de importância dos trabalhadores de ofício, assim denominados no jargão da empresa aqueles especializados em determinadas tarefas periféricas à produção, como, por exemplo, carpintaria, pintura, eletricidade, mecânica e tornearia.

A procura de trabalhadores que apliquem diversos conhecimentos e se movimentem entre vários postos de trabalho tem por conseqüência o desaparecimento dos trabalhadores de ofício. Um exemplo disso é o deslocamento, dentro da Conaprole, de trabalhadores especializados em determinados ofícios para tarefas nas quais eles já não colocam mais em prática os seus conhecimentos especializados. Essa questão cria descontentamento entre os trabalhadores pois, nos últimos anos, especialistas em determinados ofícios passaram a fazer tarefas de menor qualificação, segundo depoimentos de dirigentes sindicais.

Em relação ao conhecimento, gerentes e chefes da Conaprole assinalam a necessidade de maior capacitação, antes de mais nada, devido ao aumento dos processos automatizados e ao uso das ferramentas informáticas. No depoimento abaixo, um representante da empresa expressa a importância da competência cognitiva com a introdução da informática e de mudanças mais profundas nas relações de trabalho. Assinala que recém se está no começo, o que 
mostra a pouca extensão da capacitação entre a força de trabalho, à época da pesquisa, e que há duas tradições que se contrapõem, que ainda "têm que maturar" para chegar à compreensão da importância dessas mudanças. As duas tradições a que se refere esse representante da Conaprole são a resistência dos trabalhadores e parte da direção que ainda não daria a devida importância ao conhecimento.

Es una empresa en la cual estamos trabajando cada vez más con mayor nivel de inversión, que implica un trabajador mucho más vinculado al conocimiento [...] donde el manejo de la informática es una cosa común y todavía para hacer cambios más profundos al nivel de las relaciones de trabajo tienen que madurar más las dos partes. Son dos tradiciones [...] vamos en ese rumbo pero todavía falta (entrevista com representante da empresa).

À competência cognitiva é somada a comportamental. Observe-se as virtudes expressas por um integrante da empresa sobre a importância da autonomia e da capacidade de decisão no trabalhador requerido pela Conaprole:

[...] primero, tienen más comodidad de trabajo porque al trabajar autónomo le da confianza y trabaja con mucha más libertad. Además la satisfacción de tomar decisiones a nivel del ser humano en estos momentos es muy importante. Hay mucha cantidad de gente que sale para que le digan "hace esto, esto y esto". Es lo que te diferencia como ser humano en estas cosas. Entonces, en la medida que se lo puede ir logrando, estimularlo de esa forma, es [...] que el trabajador prefiere trabajar así. No cabe duda (entrevista com representante da empresa).

A importância da competência comportamental é afirmada também por chefes mais próximos do trabalhador. Ao ser consultado sobre a necessidade de usar uma força de trabalho flexível que aceite horários de trabalho alternativos devido à instabilidade da demanda, um chefe afirmou:

[...] tener que pensar en una persona que tenga la capacidad como para aprender, la disposición, la actitud, además contar con él en esos momentos (entrevista com representante da empresa).

Este último exemplo mostra que a Conaprole também busca uma força de trabalho com uma atitude nova, de compromisso com a empresa. No ano de 2003, a Conaprole implementou cursos internos para os supervisores nas áreas de liderança, comunicação, trabalho em equipe, tomada de decisões, seguridade e higiene, qualidade, adaptação à mudança e cultura organizacional, e normas internas da empresa. A maioria dos cursos era ministrada por 
integrantes da própria empresa, principalmente da área de Recursos Humanos. Por sua vez, o curso de adaptação à mudança e de cultura organizacional era ministrado por pessoal externo à Conaprole. Isso mostra como a empresa procurava capacitar seu quadro de supervisores, no que diz respeito a elementos inovadores da organização do trabalho presentes no capitalismo contemporâneo. Existia à época um processo de ajuste cognitivo e comportamental a uma nova organização do trabalho, através da decisão de capacitar, em primeiro lugar, o pessoal de supervisão da empresa, para depois continuar com o conjunto dos trabalhadores.

Hay temas que van a ir para abajo. Comunicación, trabajo en equipo van a ir para abajo porque el futuro es de que eso sea una competencia que va a tener que tener todo el personal. Hoy es impensable que haya alguien que no sepa o no pueda trabajar en equipo. Es básico hoy para cualquier empresa. Entonces, eso va a tener que ir para abajo. [...] Pero nosotros partimos del concepto de que la cosa tiene que venir de arriba hacia abajo. Porque de nada le sirve que yo le diga a los operarios de Conaprole "muchachos hay que trabajar en equipo", si el supervisor no está comprometido con el trabajo en equipo. Y así todo, tener que trabajar con la calidad si el supervisor no está comprometido con la calidad. Y sí, va ir para abajo. Por eso te decía, en marzo-julio del año que viene la capacitación va a tomar otra dimensión (entrevista com representante da empresa).

O projeto da Conaprole era começar a capacitação com os supervisores e depois ampliá-la para o conjunto dos trabalhadores. Isso significava que muitos supervisores ainda mantinham uma formação, à época, baseada em métodos de controle tayloristas ou mesmos pré-tayloristas (caracterizados por métodos tradicionais personalizados).

Um terceiro bloco do discurso e da política gerenciais da Conaprole enfatiza a individualização dos trabalhadores. Essa é apoiada em três pilares: a avaliação de desempenho, as gratificações por desempenho e o sistema de comunicação com os trabalhadores.

A avaliação de desempenho é um instrumento aplicado através dos supervisores. Ela atinge todos os trabalhadores e contempla cinco indicadores: (a) desempenho; (b) apresentação pessoal e disposição para o cumprimento de medidas relativas à segurança; à higiene no trabalho; e ao ordenamento e limpeza do sector: (c) cumprimento das normas internas; (d) competências; e (e) atitude para o trabalho. Os primeiros três indicadores representam dimensões que já estavam presentes no sistema de trabalho taylorista, embora pos- 
sam incluir também questões relacionadas a sistemas de organização do trabalho considerados alternativos. Por exemplo, o desempenho do trabalhador na sua atividade implica cálculo de produtividade, mas também está associado a melhora da qualidade, questão vinculada a modelos de organização do trabalho como o japonês. Do mesmo modo, o trabalhador, particularmente em indústrias de alimentação, como é o caso da empresa estudada, devia atender a questões associadas à higiene e à limpeza, bem como às normas internas da organização, mas é com o desenvolvimento dos sistemas de qualidade na produção que esses itens adquirem maior relevância. No entanto, são os dois últimos indicadores os que mais se vinculam a novos métodos de trabalho. As competências são definidas pelo grau de capacitação, experiência e habilidades do trabalhador na tarefa. Por sua vez, a atitude é dividida em duas grandes dimensões: o envolvimento com a tarefa (que inclui disposição para aceitar a supervisão e capacidade de tomar decisões); e o relacionamento com os chefes e com os outros trabalhadores (que inclui trabalho em equipe e manejo de informação com os "superiores"). Estes dois indicadores apontam, então, às competências cognitivas e comportamentais e portanto, à construção de um novo regime de mobilização da força de trabalho. Isto pode, por sua vez, significar uma modificação do habitus operário, no que diz respeito ao sistema de disposições do trabalhador na organização do trabalho.

A avaliação de desempenho na Conaprole se constitui em um índice ponderado construído com os cincos indicadores mencionados, a partir da pontuação de 1 a 7 em cada um deles. $O$ trabalhador com melhor pontuação será aquele que seja mais produtivo; exiba uma boa apresentação pessoal e disposição para cumprimento das normas de segurança, higiene, ordenamento e limpeza; cumpra com as normas internas; desenvolva competências individuais e uma atitude positiva no que diz respeito ao envolvimento com a tarefa e no relacionamento com chefes e demais trabalhadores. A direção da Conaprole procura, de um lado, uma força de trabalho produtiva, como era indicado pela organização do trabalho taylorista. Mas não apenas isso, de outro lado, também procura que a força de trabalho desenvolva uma boa disposição para desempenhar suas tarefas, mais de acordo a sistemas de trabalho como aqueles encontrados no modelo japonês e nas denominadas organizações póstayloristas, presentes, principalmente, em indústrias de processo contínuo da França, tal como foram analisados por Linhart $(1993,1994)$. 
O segundo componente das políticas adotadas pela Conaprole na direção de uma força de trabalho individualizada é o projeto gerencial de compensações por produtividade. Com isso trabalhadores considerados mais competentes receberiam gratificações por produtividade. De fato, em um acordo sobre recuperação salarial efetuado entre a direção da Conaprole e a organização sindical em 2003, foram incluídos dois artigos sobre gratificação extraordinária. O referido acordo não especifica a individualização para a estimativa do cálculo. Porém, é intenção da direção da Conaprole que esse tipo de acordo contribua para uma determinação da produtividade por trabalhador. As gratificações econômicas por produtividade (consideradas como flexibilidade salarial) já teriam sido aplicadas com os supervisores.

Los niveles superiores estamos tratando de que tengan esa flexibilidad salarial, que una parte de su retribución anual también esté vinculada al cumplimiento de los objetivos individuales y sectoriales. Siempre y cuando la empresa siga siendo rentable. No vamos a poder distribuir una mejora salarial anual, llamada bonus, premio anual o gratificación extraordinaria si no hubo un resultado positivo (entrevista com representante da empresa).

À época da pesquisa, a empresa aprovou o pagamento por produtividade aos trabalhadores, mas até esse momento, devido ao acordo com a organização sindical, sua aplicação era coletiva. Nos depoimentos a seguir, observa-se a visão empresarial das compensações por produtividade individual, as quais são vinculadas a questões analisadas neste artigo tais como o envolvimento e as competências individuais.

[...] donde incluimos por primera vez el concepto de productividad, hay que sacar la fórmula para ir involucrando a la gente, o sea, estamos en proceso, intentando cambiar la cultura predominante (Entrevista com representante da empresa).

[...] un sistema de remuneración ya sea variable, competencias laborales no hemos implementado todavía. Esa es una idea, poder pagar por objetivos cumplidos, por competencia laboral. [...] Está en las bases del convenio trabajar en lo que son productividad, y de ahí la remuneración variable. Pero recién se está constituyendo el grupo interno en Conaprole, trabajando obviamente, tratando de depurarlo bien, de saber de que estamos hablando, cuáles son los factores que vamos a tomar para hablar de trabajo en productividad, y después sí llevarlo a una paritaria con el sindicato. El tema está en pañales (entrevista com representante da empresa). 
A aplicação do conceito de produtividade individual do trabalhador encontra ainda obstáculos, como pode ser notado nos depoimentos anteriores. $\mathrm{O}$ primeiro obstáculo é a oposição do sindicato que aprova as compensações coletivas, mas não aceita que elas sejam calculadas com base na produtividade individual do trabalhador. Outro obstáculo é representado pelas concepções autoritárias de muitos supervisores, pois nesses casos a estipulação de compensações por produtividade pode se transformar em um instrumento para a diferenciação e separação dos trabalhadores.

O sistema de individualização da força de trabalho está composto por uma outra política: as comunicações escritas da empresa com o trabalhador e sua família. As cartas enviadas aos trabalhadores contemplam saudações por datas comemorativas, comunicações de sanções do trabalhador por não cumprimento de normas internas, busca de aceitação por parte do trabalhador de propostas gerenciais (por exemplo, planos de aposentadoria ou de demissão voluntária) e conflito com a organização sindical. Esses sistemas de relacionamento individualizado, com cada trabalhador, constituem o terceiro elemento que aponta para um relacionamento pessoalizado.

Os componentes do projeto de um novo regime de mobilização da força de trabalho não são compartimentos estanques, eles se relacionam uns com os outros. Assim, por exemplo, maior flexibilidade significa também aquisição de novas competências cognitivas e o desenvolvimento destas está associado aos projetos de implementação de compensações individuais por produtividade. De acordo com o analisado, a transferência de linhas de produção e o fechamento de plantas bem como novas formas de organização do trabalho representam apenas a parte mais visível das transformações em curso. A criação de um novo regime de mobilização da força de trabalho é tão importante quanto essas alterações. Para que o mesmo seja implantado, teria que ser capaz de promover a estruturação de um novo habitus operário no relativo ao desempenho e motivação do trabalhador na organização social e técnica do trabalho.

\section{Considerações finais}

Os conceitos difundidos pelos discursos gerenciais no capitalismo contemporâneo, observados na primeira parte deste trabalho, também são detec- 
tados na empresa uruguaia estudada. Trata-se de conceitos tais como flexibilidade, competência, polivalência, confiança, colaboração, envolvimento, saber-fazer, saber-ser e adaptabilidade. Isso indica que o avanço do chamado management participativo é registrado também em países periféricos como o Uruguai.

$\mathrm{Na}$ Conaprole, o discurso gerencial atribui à instabilidade do mercado global a imprescindível transformação da organização econômica e da força de trabalho.

Constata-se a presença de características pertencentes ao que Boltanski e Chiapello denominam nova ética do capitalismo, tais como a construção de uma empresa enxuta e a de trabalhadores definidos como colaboradores. $\mathrm{O}$ discurso das competências cognitivas e comportamentais mais do que das qualificações predomina também no quadro gerencial e de chefias.

A individualização na gestão dos assalariados indicada por autores como Linhart é também observada no caso estudado. Três grandes blocos fazem parte dos discursos e políticas orientadas aos trabalhadores: um primeiro sobre flexibilidade; um segundo sobre competências cognitivas e comportamentais; e um terceiro sobre individualização. Assim, predominam propostas gerenciais de flexibilidade no uso da força de trabalho e de variabilidade de horários; difunde-se por toda a organização o discurso das competências (ainda que junto com conceitos como os de polivalência e multifuncionalidade); e são instrumentados planos concretos de individualização (como a avaliação de desempenho, os sistemas de gratificação salarial e as correspondências escritas individuais para os trabalhadores). Esses constituem pilares para a construção de um novo trabalhador (combinados e solidários entre si), que estão associados a alterações na organização do trabalho.

Em suma, a busca de um novo regime de mobilização da força de trabalho, presente no que Durand (2003b) tem denominado uma nova combinatória pós-fordista, cumpre um papel importante na organização do trabalho que se vem configurando na empresa estudada. Os trabalhadores, de acordo com a visão gerencial, precisam aceitar a proposta de maior flexibilidade nas suas variadas formas e desenvolver uma identidade individual com a empresa. $\mathrm{O}$ sucesso na implantação desse novo regime de mobilização da força de trabalho dependerá não apenas da proposta gerencial, como também de outros 
fatores, entre os quais do consentimento que possa obter entre os trabalhadores assalariados.

Este artigo centrou-se na análise da busca empresarial por um novo regime de mobilização da força de trabalho, sem se deter no grau de avanço que o mesmo tem atingido na empresa pesquisada. Os resultados apresentados na tese citada (Robertt, 2006) mostraram que esse novo regime estava avançando no relativo a uma maior flexibilidade, mas encontrava dificuldades quanto ao envolvimento e à identificação individual do trabalhador com a empresa. Entre os fatores que contribuem para dificultar o envolvimento encontraram-se: o processo de enxugamento e de relocalização espacial de plantas, a persistência de relações de cunho autoritário entre supervisores e subalternos, o mercado interno segmentado de trabalhadores (com operários de diferente qualificação) e a oposição encontrada na ação sindical.

\section{Referências}

BEAUD, Stéphane; PIALOUX, Michel. Retour sur la condition ouvrière. Enquête aux usines Peugeot de Sochaux-Montbéliard. Paris: Fayard, 1999.

BOURDIEU, Pierre. Esboço de uma teoria da prática. In: ORTIZ, Renato (Org.). Pierre Bourdieu: sociologia. 2. ed. São Paulo: Ática, 1983. (Grandes CientistasSociais, 39), p. 46-81.

BOURDIEU, Pierre. A double vérité du travail. Actes de la recherche em scienses sociales. Les nouvelles formes de domination dans le travail (I). Paris, n. 114, p. 8990, sep. 1996.

DE LA GARZA TOLEDO, Enrique. La flexibilidad del trabajo en América Latina. In: DE LA GARZA TOLEDO, Enrique (Org.). Tratado latinoamericano de sociología del trabajo. México: Fondo de Cultura Económica, 2000. p. 148-178.

DURAND, Jean Pierre. A refundação do trabalho no fluxo tensionado. Tempo Social, São Paulo, v. 15, n. 1, p. 139-158, abr. 2003a.

DURAND, Jean Pierre. Les fonctionnalites de l'evaluation individuelle dans le modele de la competence. In: Contraintes, normes et competénces du travail: les regimes de mobilisation. Atelier 2. Paris: Centre Pierre Naville. Université Paris XNanterre, 2003b, p. 191-199.

GORGEU, Armelle; MATHIEU, René; PIALOUX Michel. Polyvalence, polycompétence ouvrières et intensification du travail : l'exemple de l'industrie automobile. Paris, 2003. Disponível em: <www.cee- 
recherche.fr/fr/colloque_intensification/pdf/Gorgeu\%20Matieu\%20Pialoux.pdf $>$. Acesso em: 22 fev. 2003.

HIRATA, Helena. Reorganização da produção e transformações do trabalho: uma nova divisão sexual? In: BRUSCHINI, Cristina; UNBEHAUM, Sandra G. (Org.). Gênero, democracia e sociedade brasileira. São Paulo: FCC: Ed. 34, 2002, p. 339-355.

LINHART, Danièle. À propôs du post-taylorisme. Sociologie du travail, Paris. n. 1, p. 63-74, jan. 1993.

_ La modernisation des enterprises. Paris: La decouverte, 1994.

_. Entrevista a Lucília Machado. Trabalho \& Educação, Belo Horizonte, n. 7, p. 17-22, jul.-dez., 2000.

- Organização do trabalho e participações dos assalariados: alguma novidade na França. Pro-Posições, Campinas, v. 13, n. 1, p. 34-46, jan.-abr. 2002.

MALAGUTI, Manoel Luiz. A ideologia do modelo japonês de gestão. Ensaio FEE, Porto Alegre, n. 17, p. 443-73, jan.-jun. 1996.

NARDI, Henrique Caetano. Trabalho e ética: os processos de subjetivação de duas gerações de trabalhadores metalúrgicos e do setor informal (1970-1999). 2002. Tese (Doutorado em Sociologia) - Programa de Pós-Graduação em Sociologia, Universidade Federal de Rio Grande do Sul, Porto Alegre.

NOVICK, Martha. La transformación de la organización del trabajo. In: DE LA GARZA TOLEDO, Enrique (Org.). Tratado latinoamericano de sociología del trabajo. México: Fondo de Cultura Económica, 2000, p. 123-147.

PAULANI, Leda. O papel da força viva de trabalho no processo capitalista de produção. Revista de Estudos Econômicos, São Paulo, n. 4, out.-dez. 2001.

PIALOUX, Michel. Stratégies patronales et résistances ouvrières. La "modernisation"des ateliers de finition aux usines Peugeot de Sochaux (1989-1993). Actes de la recherche em scienses sociales. Les nouvelles formes de domination dans le travail (I). Paris. n. 114, p. 5-20, sep. 1996.

ROBERTT NIZ, Pedro Alcides. Reestruturação produtiva e social em uma empresa globalizada. O caso da Conaprole no Uruguai. 2006. Tese (Doutorado em Sociologia) - Programa de Pós-Graduação em Sociologia, Universidade Federal de Rio Grande do Sul, Porto Alegre.

SUPERVIELLE, Marcos; STOLOVICH, Luis. El sociólogo del trabajo en las empresas. In: DE LA GARZA TOLEDO, Enrique (Org.). Tratado latinoamericano de sociología del trabajo. México: Fondo de Cultura Económica, 2000, p. 342-368. 